\title{
Are Low- and Middle-Income Countries Repeating Mistakes Made by High-Income Countries in the Control of HIV for Men who have Sex with Men?
}

\section{Han-Zhu Qian ${ }^{1,2 *}$ and Sten H. Vermund ${ }^{1-3}$}

${ }^{1}$ Vanderbilt Institute for Global Health, USA

${ }^{2}$ Departments of Medicine, Vanderbilt University, Nashville, Tennessee, USA

${ }^{3}$ Departments of Pediatrics, Vanderbilt University, Nashville, Tennessee, USA

Keywords: Homosexual; HIV; AIDS; Developing countries; Human rights; Transmission; Public policy; Disease control; Prevention; Antiretroviral therapy

Men who have sex with men (MSM) have been represented disproportionately in the HIV epidemic in high income countries since the first HIV/AIDS cases were reported in MSM in 1981.Among all vulnerable HIV populations, MSM account for the preponderance of prevalent AIDS cases in Western Europe [1,2]. Similarly, the largest numbers of persons with newly diagnosed HIV infections (range 45\%65\%) are MSM in the United States, Canada, Australia, and New Zealand [3-7]. In contrast, in many low- and middle-income country (LMICs) HIV epidemics were driven by injection drug use (IDU), heterosexual sex, and/or contaminated blood collection and transfusion $[8,9]$. In recent years, rapid increases in the HIV epidemic among MSM have been observed LMICs in Asia [10], Africa [11], South America [12] and Eastern Europe and Central Asia [13]. For example, MSM account for nearly one third of prevalent AIDS cases in Thailand [14] and Brazil [15], and $30 \%-75 \%$ of estimated new HIV infections in various parts of Laos and China [16,17]. A small number of epidemiologic studies have also shown high incidence (6.8/100 person-years) among MSM in Kenya and South Africa [18] and high HIV prevalence (4-23\%) in Ukraine [19], though MSM comprise a small proportion of the total HIV cases in Africa, Eastern Europe and Central Asia, perhaps due, in part, to stigmatization and underreporting.

As the HIV/AIDS epidemic enters its 4th decade post-recognition, many LMICs are repeating the mistakes made by high income countries in HIV control targeting MSM. A series of questions arise continually: Are MSM epidemics in LMICs driven by imported cases from high income countries? Have LMICs missed the window of opportunity to control the HIV epidemic among MSM? What experiences from the prevention and care for HIV among MSM populations have been learned from high income countries that could be applicable to the burgeoning MSM epidemic in LMICs?

\section{Are MSM Epidemics in LMICs Driven by Imported Cases from High Income Countries?}

Thailand is an informative case study to address the question of imported vs. autochthonous transmission of HIV among MSM. Western "sex tourists" likely contributed to the first wave of HIV epidemic among Thai MSM in the middle 1980s, judging from phylogenetic evidence (subtype/clade B virus predominated early) [20]. By the 1990s, however, subsequent waves of the epidemic of subtypes $\mathrm{E}$ and Thai subtype B (or B') were attributable to widely accessible commercial sex, IDU, heterosexual sexual transmission between couples, and from infected mothers to infants, in addition to MSM [21-23].

Was this the pattern elsewhere in Asia? Molecular epidemiology suggests imported cases to be influential among early MSM cases in Beijing, China, as the first HIV-1 recognized shared the genetic roots of viruses from the US and Western Europe [24]. Yet recent data showed the majority of infections in Chinese MSM to have a combination of HIV genotypes, with increasing genetic complexity likely a result of multiple local introductions of viruses to MSM from Chinese sub-populations infected with HIV-1 through drug injection or heterosexual transmission [25-27]. In Western Europe and North America, the early epidemic suggested an epidemic seeding different risk groups with similar viral clades and sequences, while more recent epidemic expansions of HIV to injection drug users (IDUs) in Eastern Europe have been associated with specific strains introduced and then rapidly transmitted locally [28].

Hence, HIV infections from foreign sources are typical seeding events, suggested by genetic similarities of the viruses, followed by local expansion of the epidemic from domestic sexual or drug user behaviors. For LMICs to see low MSM rates and assume that they have no problem they are missing an important lesson from the Western experience. The virus is easy to introduce, and once present, it spreads in predictable ways. This "blind spot" in policy is not unique to MSM. In Pakistan for instance, sero-prevalence in IDUs did not exceed $0.5 \%$ in most venues, and the government paid little mind; beginning in 2004, there has been an explosion of HIV transmission among IDUs in Pakistan such that current prevalence rates are typically over $15 \%$ and may reach $45 \%$ (Dr. Sharaf Ali Shah, unpublished data) [29,30].

\section{Have LMICs Missed the Window of Opportunity to Control the HIV Epidemic among MSM?}

HIV continues to spread among MSM in endemic high income countries $[28,31]$. LMICs are faced with the urgent challenge of tackling prevention challenges in this population before prevalence rates reach levels seen in the West. Given that the probability of transmission per receptive anal act of intercourse is comparatively high, LMICs can expect a rising proportion of all cases to occur among MSM in the absence of successful control [32], especially as control efforts in IDUs or heterosexual couples improve using known successful control strategies such as clean needle and syringe exchange, opiate agonist substitution therapy, and expanded combination antiretroviral therapy for prevention $[33,34]$.

${ }^{*}$ Corresponding author: Dr. Han-Zhu Qian, 2525 West End Avenue, Nashville, Tennessee 37203, USA, Tel: +1-615-343-3159; E-mail: han-zhu.qian@vanderbilt.edu

Received August 27, 2011; Accepted August 28, 2012; Published August 30 2012

Citation: Qian HZ, Vermund SH (2012) Are Low- and Middle-Income Countries Repeating Mistakes Made by High-Income Countries in the Control of HIV for Men who have Sex with Men? J AIDS Clinic Res S4:e001. doi:10.4172/2155-6113.S4-e001

Copyright: (C) 2012 Qian HZ, et al. This is an open-access article distributed under the terms of the Creative Commons Attribution License, which permits unrestricted use, distribution, and reproduction in any medium, provided the original author and source are credited. 
Human rights issues also play a role; nearly all LMICs ban or discourage marriage between homosexuals. Given poor acceptance of homosexuality societal norms, legislation, and attitudes of religious and other leaders, a failure to embrace human and civil rights for homosexuals may inhibit long-term faithful male-to-male sexual partnerships due to stigma and legal proscriptions.

MSM also face challenges related to the sexual culture prevalent particularly among many young MSM. High sexual mixing rates, concomitant non-injection drug and alcohol use, and low condom use all increase risks [35]. Sexual behavior is not easily modified by behavioral interventions; biomedical approaches such as pre-exposure prophylaxis (PrEP) are not widespread and likely not practical at a large scale over a sustained time period.

Cultural influences from high income countries, so-called "Westernization", may lead to increased social liberties and personal freedoms, including migration from home towns and villages to larger cities where they are more likely to find social and sexual groups with fewer lifestyle inhibitions [36-38]. The increased use of modern technologies such as mobile phones and the Internet allows easier access to a large social network; these modalities are used for privacy in finding friends and/or sexual partners $[39,40]$. Mainstreaming homosexual social norms without concomitant human and civil rights changes may paradoxically increase sexual mixing, without reinforcing longer-term partnerships.HIV transmission is fueled by complex social and structural issues, alongside psychological and economic ones; among these diverse themes are unrecognized HIV infection due to social stigma and structural barriers to widespread testing, larger social/sexual networks, fear of accessing stigmatized HIV clinical care or prevention services, male sex work, and a history of childhood sexual abuse [41].

Countries experiencing rapid development of globalized market economies tend to lose prior strict religious or other social taboos that kept homosexuality underground and suppressed, e.g., China, Brazil, Mexico, South Africa, Vietnam, Peru, many Caribbean nations [4245]. Even lower income nations such as Malawi and Uganda are facing the clash of vicious homophobia from political and religious circles, met with human rights activities often driven by MSM themselves $[46,47]$. It may be a matter of time before issues of sexual orientation are viewed with more tolerance worldwide (note recent actions by the new Malawian President Joyce Banda to make clear her opposition to criminalization of homosexual activity); in a more open and engaged environment, public health, political, religious, and community activist leaders can work with more synergy with afflicted communities. Given that testing and linkage to care seem to be among the most promising prevention strategies [48], openness and engagement are essential prerequisites for successful programs [47,49-52].

\section{What Experiences from the Prevention and Care for HIV among MSM Populations Have Been Learned from High Income Countries That Could Be Applicable to LMICs?}

Some intervention approaches have been applied in public health programs for effectively preventing HIV in IDUs, commercial sex workers, and other vulnerable groups. For example, "100\% condom programs" successfully reversed the rapid rising HIV epidemic in FSWs in Thailand [53]. Implementation of large-scale needle exchange and methadone substitution programs has led substantial decline of HIV new infections among drug injectors worldwide, including recent successes in China [54,55]. Closing illicit plasma collection stations also helped eliminating HIV spread among plasma donors in China [56]. However, public health programs have been underwhelming in their successes in controlling the HIV epidemic among MSM. Perhaps the most promising is the mixture of structural and behavioral approaches to implement expanded testing and linkage to care in San Francisco and Vancouver where early data suggest a possible decline in HIV incidence as antiretroviral treatment reaches more persons [57-59]. LMICs with increasing HIV transmission and sero-conversions among MSM are similarly constrained as to the tools available that are likely to tackle this challenge.

In high income nations, significant ethnic disparities in HIV risk among MSM have been documented; Black and Hispanic MSM have higher risks of infection than their white counterparts, though their risk behavior profiles are not very different $[41,60,61]$. The higher HIV risk in Black MSM is almost certainly not contributable to more risky sexual behaviors, but is more likely due to higher prevalence rates in sexual networks, structural barriers to safer sex and access to services; high prevalence backgrounds would increase HIV risk, and social factors could also exacerbate risk, including lower socio-economic status, less health insurance, lower access to HIV antiretroviral therapy and other HIV care [60]. As long as MSM communities continue to endure stigma, discrimination, and unavailability of HIV services, LMICs can expect HIV to rise among MSM.

Although PrEP intervention has shown promise for preventing HIV among MSM, including iPrEx study [62], this was in an optimized clinical trial setting. More operational research is needed for effective and safe deployment of innovative interventions into public health programs in LMICs. Given gaps in treatment coverage, it is improbable that policymakers will use AIDS monies for PrEP when ART is lacking for HIV sero-positive persons. The importance and value of engaging MSM communities in such operational research is one lesson to take from high income country experiences. MSM community activists have contributed substantially to HIV/AIDS research by suggesting concepts, engaging communities, and educating policymakers, among many other roles in both prevention and therapeutic arenas [63].

No behavioral study of MSM has demonstrated a significant and sustained impact on HIV sero-incidence among MSM. Nonetheless, the US CDC have identified prevention interventions targeting HIVinfected or non-infected MSM that have had a significant impact on self-reported behavioral risks, including HIV testing and linkage to care, antiretroviral therapy (ART), access to condoms and sterile syringes, screening and treatment for other sexually transmitted infections, and others [64-75]. For successful control of HIV in MSM, experts believe that integrated combination prevention approaches are needed. For example, expanding HIV testing and linkage to care based on antiretroviral therapy and additional therapeutic attention to such comorbidities as tuberculosis, mental health and substance use issues, and nutritional deficiencies are worthy of testing among MSM as is being done for general populations in such studies as the HIV Prevention Trials Network (HPTN) 065 and 071 protocols, the ANRS/Africa Centre study, and Iringa and Botswana studies. The implementation science work to improve the continuum of HIV care is essential. Even in the high income US, among an estimated 1.2 million HIV-infected Americans, only about one third are on ART and a quarter are virally suppressed [76]. The theory behind test-link-care is that the amount of virus circulating in a community will decline with the increase in HIVinfected persons who know their status, are effectively linked to and retained in antiretroviral therapy (ART)-based care, and who adhere to 
Citation: Qian HZ, Vermund SH (2012) Are Low- and Middle-Income Countries Repeating Mistakes Made by High-Income Countries in the Control of HIV for Men who have Sex with Men? J AIDS Clinic Res S4:e001. doi:10.4172/2155-6113.S4-e001

their medicines and change behaviors to reduce risk of transmitting the virus [58,77-80]. This approach is challenging [81], but may represent the best public health opportunity for LMICs to control the epidemic in MSM.

\section{Acknowledgements}

This work was sponsored by U.S. National Institute of Health grants R01AI094562 and R34AI091446.

\section{References}

1. Behforouz HL, Kalmus A, Scherz CS, Kahn JS, Kadakia MB, et al. (2004) Directly observed therapy for HIV antiretroviral therapy in an urban US setting. J Acquir Immune Defic Syndr 36: 642-645.

2. Van der Poel GGF, Love L (2006) Behavioral risk exclusion in Europe in response to MSM discussion.

3. El-Sadr WM, Mayer KH, Hodder SL (2010) AIDS in America--forgotten but not gone. N Engl J Med 362: 967-970

4. Public Health Agency of Canada (2010) HIVIAIDS Epi Updates, July, Surveillance and Risk Assessment Division of the Centre for Communicable Diseases and Infection Control, Canada.

5. Centers for Disease Control and Prevention (2012) HIV among Gay and Bisexual Men. Divisions of HIVIAIDS Prevention, National Center for HIVIAIDS, Viral Hepatitis, STD, and TB Prevention, U.S.

6. Pedrana A, Guy R, Bowring A, Hellard M, Stoove M (2011) Community models for HIV testing for MSM: Systematic Review.

7. Saxton PJ, Dickson NP, McAllister SM, Sharples K, Hughes AJ (2011) Increase in HIV diagnoses among men who have sex with men in New Zealand from a stable low period. Sex Health 8: 311-318.

8. Beyrer C, Baral SD, Walker D, Wirtz AL, Johns B, et al. (2010) The expanding epidemics of HIV type 1 among men who have sex with men in low- and middleincome countries: diversity and consistency. Epidemiol Rev 32: 137-151.

9. UNAIDS (2012) Global AIDS Response Progress Reporting 2012

10. van Griensven F, de Lind van Wijngaarden JW (2010) A review of the epidemiology of HIV infection and prevention responses among MSM in Asia. AIDS 3: S30-S40.

11. Mclntyre JA (2010) The need for HIV prevention interventions for men who have sex with men in Africa. Sex Transm Infect 86: 82-83.

12. Baral S, Sifakis F, Cleghorn F, Beyrer C (2007) Elevated risk for HIV infection among men who have sex with men in low- and middle-income countries 2000 2006: a systematic review. PLoS Med 4: e339.

13. Bridge J, Lazarus JV, Atun R (2010) HIV epidemics and prevention responses in Asia and Eastern Europe: lessons to be learned? AIDS 24: S86-S94.

14. UNAIDS (2008) 2008 Report on the global AIDS epidemic. Geneva.

15. Brazilian Ministry of Health (2012) Progress Report on the Brazilian Response to HIVIAIDS (2010-2011)

16. Lyttleton C (2008) Mekong Erotics: Men Loving/Pleasuring/Using Men in Lao PDR. UNESCO Bangkok.

17. Ministry of Health of the People's Republic of China, Joint United Nations Programme on HIVIAIDS, Organization WH (2009) Estimates for the HIVIAIDS Epidemic in China.

18. Price MA, Rida W, Mwangome M, Mutua G, Middelkoop K, et al. (2012) Identifying at-risk populations in Kenya and South Africa: HIV incidence in cohorts of men who report sex with men, sex workers, and youth. J Acquir Immune Defic Syndr 59: 185-193.

19. National AIDS Prevention Centre/Ministry of Health Information bulletin No 29. HIV infection in Ukraine in 2007. Kyiv: National AIDS Prevention Centre/ Ministry of Health, 2008.

20. Weniger BG, Takebe Y, Ou CY, Yamazaki S (1994) The molecular epidemiology of HIV in Asia. AIDS 8: S13-S28.

21. Weniger BG, Limpakarnjanarat K, Ungchusak K, Thanprasertsuk S, Choopanya $\mathrm{K}$, et al. (1991) The epidemiology of HIV infection and AIDS in Thailand. AIDS 5: S71-S85.
22. Kalish ML, Luo CC, Weniger BG, Limpakarnjanarat K, Young N, et al. (1994) Early HIV type 1 strains in Thailand were not responsible for the current epidemic. AIDS Res Hum Retroviruses 10: 1573-1575.

23. Cleghorn FR, Jack N, Carr JK, Edwards J, Mahabir B, et al. (2000) A distinctive clade B HIV type 1 is heterosexually transmitted in Trinidad and Tobago. Proc Natl Acad Sci U S A 97: 10532-10537.

24. Yao J, Zhang F, He ZP, Zhao HX, Li XW, et al. (2002) Subtype and sequence analysis of the C2-V3 region of env gene among HIV-1 infected homosexual men in Beijing. Chin J STD AIDS Prev Control 8: 131-133.

25. Wang W, Jiang S, Li S, Yang K, Ma L, et al. (2008) Identification of subtype B, multiple circulating recombinant forms and unique recombinants of HIV type 1 in an MSM cohort in China. AIDS Res Hum Retroviruses 24: 1245-1254.

26. Li L, Lu X, Li H, Chen L, Wang Z, et al. (2011) High genetic diversity of HIV-1 was found in men who have sex with men in Shijiazhuang. China. Infect Genet Evol 11: 1487-1492.

27. Li L, Sun G, Li T, Liu Y, Chen L, et al. (2012) Multiple Introductions of HIV into Men Who Have Sex with Men Were Found in Zhengzhou City, China. AIDS Res Hum Retroviruses 28: 947-951.

28. Vermund SH, Leigh-Brown AJ (2012) The HIV Epidemic: High-Income Countries. Cold Spring Harb Perspect Med 2: a007195.

29. Vermund SH, White H, Shah SA, Altaf A, Kristensen S, et al. (2006) HIVIAIDS in Pakistan: has the explosion begun? J Pak Med Assoc 56: S1-S2.

30. Shah SA, Altaf A, Mujeeb SA, Memon A (2006) An outbreak of HIV infection among injection drug users in a small town of Pakistan: potential for national implications. J Pak Med Assoc 56: S77.

31. Sullivan PS, Hamouda O, Delpech V, Geduld JE, Prejean J, et al. (2009) Reemergence of the HIV epidemic among men who have sex with men in North America, Western Europe, and Australia, 1996-2005. Ann Epidemiol 19: 423-431.

32. Beyrer C, Baral SD, van Griensven F, Goodreau SM, Chariyalertsak S, et al. (2012) Global epidemiology of HIV infection in men who have sex with men. Lancet 380: 367-377.

33. Burns DN, Dieffenbach CW, Vermund SH (2010) Rethinking prevention of HIV type 1 infection. Clin Infect Dis 51: 725-731.

34. Kurth AE, Celum C, Baeten JM, Vermund SH, Wasserheit JN (2011) Combination HIV prevention: significance, challenges, and opportunities. Curr HIVIAIDS Rep 8: 62-72.

35. Vermund SH, Allen KL, Karim QA (2009) HIV-prevention science at a crossroads: advances in reducing sexual risk. Curr Opin HIV AIDS 4: 266-273.

36. He Q, Xia Y, Raymond HF, Peng R, Yang F, Ling L (2011) HIV trends and related risk factors among men having sex with men in mainland China: findings from a systematic literature review. Southeast Asian J Trop Med Public Health 42 616-633.

37. Egan JE, Frye V, Kurtz SP, Latkin C, Chen M, et al. (2011) Migration, neighborhoods, and networks: approaches to understanding how urban environmental conditions affect syndemic adverse health outcomes among gay, bisexual and other men who have sex with men. AIDS Behav 15: S35-S50.

38. Jolly S, Reeves H (2005) Gender and Migration. Bridge, Institute of Development Studies (IDS), London, UK.

39. Ogilvie GS, Taylor DL, Trussler T, Marchand R, Gilbert M, et al. (2008) Seeking sexual partners on the internet: a marker for risky sexual behaviour in men who have sex with men. Can J Public Health 99: 185-188.

40. Smith DM, Drumright LN, Frost SD, Cheng WS, Espitia S, et al. (2006) Characteristics of recently HIV-infected men who use the Internet to find male sex partners and sexual practices with those partners. J Acquir Immune Defic Syndr 43: 582-587.

41. Feldman MB (2010) A critical literature review to identify possible causes of higher rates of HIV infection among young black and Latino men who have sex with men. J Natl Med Assoc 102: 1206-1221.

42. Liu $H$, Yang $H$, Li X, Wang $N$, Liu $H$, et al. (2006) Men who have sex with men and human immunodeficiency virus/sexually transmitted disease control in China. Sex Transm Dis 33: 68-76.

43. Caceres CF (2002) HIV among gay and other men who have sex with men in Latin America and the Caribbean: a hidden epidemic? AIDS 16: S23-S33. 
Citation: Qian HZ, Vermund SH (2012) Are Low- and Middle-Income Countries Repeating Mistakes Made by High-Income Countries in the Control of HIV for Men who have Sex with Men? J AIDS Clinic Res S4:e001. doi:10.4172/2155-6113.S4-e001

44. Van Griensven F, de Lind van Wijngaarden JW, Baral S, Grulich A (2009) The global epidemic of HIV infection among men who have sex with men. Curr Opin HIV AIDS 4: 300-307.

45. Berry MC, Go VF, Quan VM, Minh NL, Ha TV, et al. (2012) Social environment and HIV risk among MSM in Hanoi and Thai Nguyen. AIDS Care.

46. Ross MW, Smolenski DJ, Kajubi P, Mandel JS, McFarland W, et al. (2010) Measurement of internalized homonegativity in gay and bisexual men in Uganda: Cross-cultural properties of the Internalized Homonegativity scale. Psychol Health Med 15: 159-165.

47. Fay H, Baral SD, Trapence G, Motimedi F, Umar E, et al. (2011) Stigma, health care access, and HIV knowledge among men who have sex with men in Malawi, Namibia, and Botswana. AIDS Behav 15: 1088-1097.

48. Cohen MS, Chen YQ, McCauley M, Gamble T, Hosseinipour MC, et al. (2011) Prevention of HIV-1 infection with early antiretroviral therapy. N Engl J Med 365: 493-505.

49. Beyrer C, Sullivan PS, Sanchez J, Dowdy D, Altman D, et al. (2012) A call to action for comprehensive HIV services for men who have sex with men. Lancet 380: 424-438.

50. Trapence G, Collins C, Avrett S, Carr R, Sanchez H, et al. (2012) From personal survival to public health: community leadership by men who have sex with men in the response to HIV. Lancet 380: 400-410.

51. Baral S, Adams D, Lebona J, Kaibe B, Letsie P, et al. (2011) A cross-sectional assessment of population demographics, HIV risks and human rights contexts among men who have sex with men in Lesotho. J Int AIDS Soc 14: 36

52. Baral S, Trapence G, Motimedi F, Umar E, lipinge S, et al. (2009) HIV prevalence, risks for HIV infection, and human rights among men who have sex with men (MSM) in Malawi, Namibia, and Botswana. PLoS One 4: e4997.

53. Kilmarx PH, Palanuvej T, Limpakarnjanarat K, Chitvarakorn A, St Louis ME, et al. (1999) Seroprevalence of HIV among female sex workers in Bangkok: evidence of ongoing infection risk after the "100\% condom program" was implemented. J Acquir Immune Defic Syndr 21: 313-316.

54. Ni M, Fu L, Chen X, Hu X, Wheeler K (2012) Net financial benefits of averting HIV infections among people who inject drugs in Urumqi, Xinjiang, Peoples Republic of China (2005¿2010). BMC Public Health 12: 572.

55. Guinness L, Vickerman P, Quayyum Z, Foss A, Watts C, et al. (2010) The costeffectiveness of consistent and early intervention of harm reduction for injecting drug users in Bangladesh. Addiction 105: 319-328.

56. Qian HZ, Vermund SH, Wang N (2005) Risk of HIVIAIDS in China: subpopulations of special importance. Sex Transm Infect 81: 442-447.

57. Das M, Chu PL, Santos GM, Scheer S, Vittinghoff E, et al. (2010) Decreases in community viral load are accompanied by reductions in new HIV infections in San Francisco. PLoS One 5: e11068.

58. Lima VD, Johnston K, Hogg RS, Levy AR, Harrigan PR, et al. (2008) Expanded access to highly active antiretroviral therapy: a potentially powerful strategy to curb the growth of the HIV epidemic. J Infect Dis 198: 59-67.

59. O'Shaughnessy MV, Hogg RS, Strathdee SA, Montaner JS (2012) Deadly Public Policy: What the Future Could Hold for the HIV Epidemic among Injection Drug Users in Vancouver. Curr HIVIAIDS Rep.

60. Millett GA, Peterson JL, Flores SA, Hart TA, Jeffries WL 4th, et al. (2012) Comparisons of disparities and risks of HIV infection in black and other men who have sex with men in Canada, UK, and USA: a meta-analysis. Lancet 380: 341-348.

61. Koblin B, Mayer KH, Eshleman S, Wang L, Shoptaw C, et al. (2012) Correlates of HIV incidence among black men who have sex with men in 6 U.S. cities (HPTN 061). 9th International AIDS Conference, abstract MOAC0106, Washington, DC

62. Grant RM, Lama JR, Anderson PL, McMahan V, Liu AY, et al. (2010) Preexposure chemoprophylaxis for HIV prevention in men who have sex with men. N Engl J Med 363: 2587-2599.

63. Killen J, Harrington M, Fauci AS (2012) MSM, AIDS research activism, and HAART. Lancet. 380: 314-316.

64. Fisher HH, Patel-Larson A, Green K, Shapatava E, Uhl G, et al. (2011) Evaluation of an HIV prevention intervention for African Americans and Hispanics: findings from the VOICES/VOCES Community-based Organization Behavioral Outcomes Project. AIDS Behav 15: 1691-1706.
65. Owczarzak J, Dickson-Gomez J (2011) Providers' perceptions of and receptivity toward evidence-based HIV prevention interventions. AIDS Educ Prev 23: 105117.

66. Owczarzak J, Dickson-Gomez J (2011) Provider perspectives on evidencebased HIV prevention interventions: barriers and facilitators to implementation AIDS Patient Care STDS 25: 171-179.

67. Bowen SA, Saunders RP, Richter DL, Hussey J, Elder K, et al. (2010) Assessing levels of adaptation during implementation of evidence-based interventions: introducing the Rogers-Rutten framework. Health Educ Behav 37: 815-830.

68. Margaret Dolcini M, Gandelman AA, Vogan SA, Kong C, Leak TN, et al. (2010) Translating HIV interventions into practice: community-based organizations' experiences with the diffusion of effective behavioral interventions (DEBIs) Soc Sci Med 71: 1839-1846.

69. Pemberton G, Andía J, Robles R, Collins C, Colón-Cartagena N, et al. (2009) From research to community-based practice--working with Latino researchers to translate and diffuse a culturally relevant evidence-based intervention: the Modelo de Intervencion Psicomedica (MIP) experience. AIDS Educ Prev 21: 171-185.

70. Stallworth JM, Andía JF, Burgess R, Alvarez ME, Collins C (2009) Diffusion of Effective Behavioral Interventions and Hispanic/Latino populations. AIDS Educ Prev 21: 152-163.

71. Rotheram-Borus MJ, Swendeman D, Flannery D, Rice E, Adamson DM, et al. (2009) Common factors in effective HIV prevention programs. AIDS Behav 13: 399-408.

72. Dworkin SL, Pinto RM, Hunter J, Rapkin B, Remien RH (2008) Keeping the spirit of community partnerships alive in the scale up of HIVIAIDS prevention: critical reflections on the roll out of DEBI (Diffusion of Effective Behavioral Interventions). Am J Community Psychol 42: 51-59.

73. Collins C, Phields ME, Duncan T (2007) An agency capacity model to facilitate implementation of evidence-based behavioral interventions by communitybased organizations. J Public Health Manag Pract S16-S23.

74. Harshbarger C, Simmons G, Coelho H, Sloop K, Collins C (2006) An empirical assessment of implementation, adaptation, and tailoring: the evaluation of CDC's National Diffusion of VOICES/VOCES. AIDS Educ Prev 18: 184-197.

75. Wingood GM, DiClemente RJ (2006) Enhancing adoption of evidence-based HIV interventions: promotion of a suite of HIV prevention interventions for African American women. AIDS Educ Prev 18: 161-170.

76. (2011) Vital signs: HIV prevention through care and treatment--United States. MMWR Morb Mortal Wkly Rep 60: 1618-1623.

77. Granich RM, Gilks CF, Dye C, De Cock KM, Williams BG (2009) Universal voluntary HIV testing with immediate antiretroviral therapy as a strategy for elimination of HIV transmission: a mathematical model. Lancet 373: 48-57.

78. Dieffenbach CW, Fauci AS (2009) Universal voluntary testing and treatment for prevention of HIV transmission. JAMA 301: 2380-2382.

79. Vermund SH, Hodder SL, Justman JE, Koblin BA, Mastro TD, et al. (2010) Addressing research priorities for prevention of HIV infection in the United States. Clin Infect Dis 50: S149-S155.

80. Wagner BG, Kahn JS, Blower S (2010) Should we try to eliminate HIV epidemics by using a 'Test and Treat' strategy? Aids 24: 775-776.

81. Vermund SH, Sidat M, Weil LF, Tique JA, Moon TD, et al. (2012) Transitioning HIV care and treatment programs in southern Africa to full local management. Aids 26: 1303-1310.

This article was originally published in a special issue, Epidemiology and Prevention: HIV handled by Editor(s). Dr. Han-zhu Qian, Vanderbilt University School of Medicine, USA 